\title{
Long-Term Follow-Up of a High School Alcohol Misuse Prevention Program's Effect on Students' Subsequent Driving
}

\author{
Jean T. Shope, Michael R. Elliott, Trivellore E. Raghunathan, and Patricia F. Waller
}

\begin{abstract}
Background: Alcohol-related injuries, particularly motor vehicle, are an important cause of adolescent mortality. School-based alcohol prevention programs have not been evaluated in terms of driving outcomes. This study examined the effects on subsequent driving of a high school-based alcohol prevention program.

Methods: The Alcohol Misuse Prevention Study included a randomized test of the effectiveness of an alcohol misuse prevention curriculum conducted among 4635 10th-grade students. Students were assigned to intervention $(n=1820)$ or control $(n=2815)$ groups and were followed for an average of 7.6 years after licensure, which typically occurred during or shortly after 10th grade. Outcomes examined included alcohol-related and other serious offenses, and at-fault, single-vehicle, and alcohol-related crashes.

Results: Only serious offenses (which included alcohol-related) had a significant treatment effect (statistically marginal) after we adjusted for sex, age, race, alcohol use/misuse, family structure, presence of prelicense offenses, age of driver licensure, and parental attitudes toward teen drinking. The effect was found only during the first year of licensure (estimated adjusted relative risk $=0.80$, confidence interval $=$ $0.63-1.01$ ). Two first-year serious offense interactions were found. The positive effect was strongest among the largest subgroup of students, those who were drinking less than one drink per week on average before the curriculum, compared with those who drank more than one drink per week $(p=0.009)$. The effect was also stronger for the small subgroup of students whose parents had not expressed disapproval of teens' drinking, compared with those whose parents had disapproved $(p=0.004)$.

Conclusions: These findings suggest that a high school-based alcohol prevention program can positively affect subsequent driving, particularly that of students who do not use alcohol regularly. The results highlight the need to start prevention efforts early and extend them beyond the initial exposure to driving. Programs should incorporate the differing backgrounds of the students.
\end{abstract}

Key Words: Adolescents, School-Based Prevention, Alcohol Drinking, Automobile Driving, Accidents, Traffic.

$I^{N}$ NJURY, MOTOR VEHICLE injury in particular, is the major cause of death and disability among adolescents and young adults, and alcohol is involved in a considerable proportion of these injuries (Institute of Medicine, 1999; Insurance Institute for Highway Safety, 1998; National Highway Traffic Safety Administration, 1998). Despite recent downturns in reported alcohol use by high school students, alcohol misuse continues to be a serious problem (Monitoring the Future Study, 1999) that leaves young

From the Transportation Research Institute (JTS, MRE, PFW) and Department of Biostatistics (TER), University of Michigan, Ann Arbor, Michigan.

Received for publication March 14, 2000; accepted December 15, 2000. Supported by Grants RO1 AA 06324 and RO1 AA 09026 from NIAAA.

An earlier version of this paper was presented at the 22nd Annual Scientific Meeting of the Research Society on Alcoholism, June 26-July 1, 1999, Santa Barbara, California.

Reprint requests: Jean T. Shope, PhD, MSPH, University of Michigan Transportation Research Institute, 2901 Baxter Road, Ann Arbor, MI 481092150; Fax: 734-936-1076; E-mail: jshope@umich.edu

Copyright (C) 2001 by the Research Society on Alcoholism. people particularly vulnerable to injuries and fatalities as a result.

Although school-based alcohol prevention programs have the reduction of such outcomes as their ultimate goal, such outcomes are seldom measured. Instead, more immediate outcomes, such as alcohol-related knowledge, attitudes, intentions, and behavior usually are measured by self-reports. A review of school-based programs for preventing drinking and driving (Mann et al., 1986) noted that although certain types of programs resulted in immediate knowledge gains as well as appropriate changes in attitudes and self-reported behavior, these effects dissipated with time. Furthermore, the authors stated that the impact of these programs on traffic safety needed documentation.

Several high school-based prevention programs recently have been developed and evaluated. "Alcohol, Drugs, Driving and You," a 10th-grade curriculum, resulted in increased knowledge and more favorable attitudes (Young, 1991). "Stop the Drinking Driver," a behavioral schoolbased program that targeted all students in a high school, found that after the program, students reported they were 
less likely to drive while intoxicated (Yates and Dowrick, 1991). A ninth-grade program aimed at reducing drinking, drinking and driving, and riding with a drinking driver significantly increased knowledge and perceived ability to resist pressures to drink but did not change self-reported drinking or in drinking and driving (Newman et al., 1992). An innovative "Teams, Games, Tournaments" alcohol and driving education program produced initial and subsequent positive effects on knowledge, self-reported drinking, and drinking and driving and suggested that future studies analyze drinking/driving citation outcomes (Wodarski and Bordnick, 1994). In Australia, a 10th-grade drinking/driving education program produced a trend toward less drinking/ driving in the intervention group, although both experimental groups reduced this behavior during the 3-year follow-up period (Sheehan et al., 1996). As part of the Minnesota Heart Health Program, a ninth-grade program, "Shifting Gears," which addressed smoking, alcohol use, drinking and driving behavior, and marijuana use, resulted in less drinking, problem drinking, and driving after drinking shortly after the program, but the effects were not maintained (Klepp et al., 1995). The authors suggested the need for supportive community-wide strategies to maintain the desired behaviors.

Project Northland's school interventions (beginning with sixth-grade students and continuing through high school) included community action in an ambitious, comprehensive, prevention approach that also included parent education and involvement (Williams and Perry, 1998; Williams et al., 1999). The 12th-grade outcome results, which follow high school intervention activities, are still forthcoming (Perry et al., 2000), but at the end of 11th grade, the intervention students were drinking less (although not significantly so). Among baseline (sixth-grade) nonusers, however, marginally significant differences were found. This major study presents an ideal opportunity to learn if the driving behavior of the young people involved is positively affected by the interventions.

Ideally, one would want to track behavior well beyond those immediate outcomes, problems, and consequences that are primarily tied to the use of alcohol, to include injury-related behaviors as well. It is particularly important to monitor the subsequent driving behaviors of students exposed to a prevention program. The long-term evaluation of one school-based alcohol misuse prevention program was later funded to study the driving behavior of the subjects on whom much data had been collected. The high school Alcohol Misuse Prevention Study (AMPS) curriculum was effective in increasing students' alcohol misuse prevention knowledge and alcohol refusal skills and in reducing alcohol misuse (Shope et al., 1993, 1996a). It was, however, important to determine if these positive effects extended to the students' driving behaviors. Preliminary results of driving outcomes from the first 2 years were promising and showed a positive program effect on the number of serious offenses (Shope et al., 1996b). As the subjects gained more driving experience (as indicated by years of licensure), the program effects over a longer time period could be examined. The purpose of this study was to determine if the high school alcohol misuse prevention curriculum showed positive effects over several years of the students' subsequent driving behavior, and we focused particularly on alcohol-related offenses or crashes.

\section{METHODS}

\section{Sample and Sources of Data}

In the 1988-89 and 1989-90 school years, 10th graders (graduating classes of 1991 and 1992) in six school districts in southeastern Michigan participated in AMPS, an ongoing study that had begun when those students were in fifth and sixth grades (Dielman et al., 1989; Shope et al., 1992). All available students with parental permission participated in a fall survey, which served as a pretest to the curriculum that followed later that same school year. Classes of students within districts were assigned randomly to receive the AMPS curriculum taught by project staff or to serve as controls. This was achieved either by randomly selecting one-half of the classes in a required course or by teaching the curriculum during second, rather than first, semester health classes. (School personnel told the investigators that the assignment of students to semesters was essentially random.) In the smallest district, only students whose teachers volunteered for AMPS received the curriculum, and one district declined the intervention. Follow-up surveys were conducted 2 months after the curriculum and again with 12th graders in 1991 and 1992.

Information about traffic offenses and reported crashes between 1986 and 1997 was obtained from Michigan's driver history files for all participating students who obtained a driver's license in Michigan by June 1997. The subjects used in these analyses were restricted to those who participated in the 10th-grade pretest and who had obtained a Michigan driver's license by June 1997. A total of 6081 students participated in the 1988 or 1989 pretest, nearly $90 \%$ of all enrolled at that time. Of the 6081 subjects, $4635(76 \%)$ obtained a driver's license by June 1997: 1820 intervention and 2815 control subjects. These students were clustered in 254 classrooms.

\section{Curriculum}

Students randomized to the intervention received the AMPS curriculum (Shope et al., 1989) in five sessions, described in detail in Table 1. The 45 min sessions were delivered on consecutive days. The curriculum was developed to serve as fresh material for those new to the program but at the same time to augment earlier material for those who had participated previously. Goals of the curriculum included increasing student awareness of the short-term effects of alcohol, risks of alcohol misuse (including drinking and driving), and situations and social pressures to misuse alcohol that students might encounter. Students were introduced to skills for dealing with such pressures and situations to "inoculate" them against peer and other social pressures to misuse alcohol (Evans, 1976). Audiovisual materials, student activity sheets, and handouts were used to maintain student interest. Positive effects of the curriculum on students' knowledge, alcohol misuse, and refusal skills were found at the 12th-grade follow-up (Shope et al., 1996b).

To ensure that the curriculum was standardized and implemented as designed, certified teachers were hired and trained, and their teaching was monitored. Teacher self-ratings on achievement of objectives, coverage of topics, and overall performance averaged 4.59 on a 1 (not very well) to 5 (very well) scale. A pair of trained raters with high interrater agreement gave mean evaluations of 4.63 out of 5 on a similar 1 to 5 scale that rated 10 specific performance objectives (Shope et al., 1996b). 
Table 1. Summary of Alcohol Misuse Prevention Study (AMPS) 10th-Grade Curriculum

\begin{tabular}{|c|c|c|c|}
\hline & Goal & Objectives & Activities \\
\hline Session 1 & $\begin{array}{l}\text { Help students learn key facts about } \\
\text { alcohol and its short-term } \\
\text { effects, the risks of drinking and } \\
\text { driving, and the risks of alcohol } \\
\text { misuse. }\end{array}$ & $\begin{array}{l}\text { 1. Explain three facts about alcohol and its } \\
\text { short-term effects. } \\
\text { 2. Recognize the potential health, social, } \\
\text { and legal risks of alcohol misuse. } \\
\text { 3. Recognize the potential consequences } \\
\text { of alcohol misinformation. }\end{array}$ & $\begin{array}{l}\text { Introduction; worksheet done in small groups; } \\
\text { game; poster for class; pamphlets for each } \\
\text { student; anticipation of next session. }\end{array}$ \\
\hline Session 2 & $\begin{array}{l}\text { Provide students an understanding } \\
\text { of the concepts of group norms, } \\
\text { expectations, and peer pressure, } \\
\text { their influence on behaviors, and } \\
\text { influences on people to drink } \\
\text { alcohol. }\end{array}$ & $\begin{array}{l}\text { 1. Identify and define two examples of } \\
\text { group norms, applying the terms } \\
\text { expectations and positive and negative } \\
\text { outcomes to typical behaviors. } \\
\text { 2. Identify ways in which peer group } \\
\text { norms influence people to behave in } \\
\text { certain ways that may have negative } \\
\text { consequences. } \\
\text { 3. Recognize different appeals that } \\
\text { advertisers use to influence people to } \\
\text { use alcohol. } \\
\text { 4. Identify other influences on people to } \\
\text { use alcohol. }\end{array}$ & $\begin{array}{l}\text { Review; class discussion; worksheets; } \\
\text { transparencies; conflict situations with } \\
\text { questions for small groups; TV alcohol } \\
\text { advertisements on video; anticipation of } \\
\text { the next session. }\end{array}$ \\
\hline Session 3 & $\begin{array}{l}\text { Help student analyze how } \\
\text { advertising, role models, } \\
\text { availability of alcohol, and offers } \\
\text { of a drink influence people to } \\
\text { use alcohol. Help students } \\
\text { understand the need to control } \\
\text { one's own health. Provide } \\
\text { students with opportunities to } \\
\text { analyze typical drinking } \\
\text { situations in terms of the } \\
\text { pressures and } \\
\text { outcomes of alcohol } \\
\text { use versus non-use. }\end{array}$ & $\begin{array}{l}\text { 1. Understand how role models, } \\
\text { availability, offers to drink, advertising, } \\
\text { and peer pressure influence people to } \\
\text { use alcohol. } \\
\text { 2. Identify the similar appeals used in all } \\
\text { these pressures. } \\
\text { 3. Understand that each person is } \\
\text { responsible for his/her own health and } \\
\text { that the support of friends can be } \\
\text { helpful. } \\
\text { 4. Recognize that avoiding potential } \\
\text { drinking and driving situations is the } \\
\text { most effective way to reduce one's risk } \\
\text { of incurring the negative consequences } \\
\text { of drinking and driving. }\end{array}$ & $\begin{array}{l}\text { Review; pressure situation worksheets for } \\
\text { small groups; class discussion; trust walk; } \\
\text { booklets for each student; anticipation of } \\
\text { the next session. }\end{array}$ \\
\hline Session 4 & $\begin{array}{l}\text { Provide students with opportunities } \\
\text { to develop strategies to resist } \\
\text { pressure to use/misuse alcohol } \\
\text { in typical drinking and driving } \\
\text { situations. }\end{array}$ & $\begin{array}{l}\text { 1. Give examples of strategies to resist } \\
\text { pressure from direct offers, availability, } \\
\text { role models, and seeing others drink. } \\
\text { 2. Develop strategies to resist pressure to } \\
\text { use/misuse alcohol and to ride with an } \\
\text { impaired driver and to help friends resist } \\
\text { these pressures. } \\
\text { 3. Begin to use strategies developed. }\end{array}$ & $\begin{array}{l}\text { Review; class discussion; conflict situations } \\
\text { for discussion, development and practice } \\
\text { of resistance strategies; role play } \\
\text { development; anticipation of the next session. }\end{array}$ \\
\hline Session 5 & $\begin{array}{l}\text { Provide students further practice in } \\
\text { using and improving strategies to } \\
\text { resist pressure to drink alcohol } \\
\text { and in helping friends resist } \\
\text { pressure in drinking and driving } \\
\text { situations. Provide students an } \\
\text { opportunity to apply alcohol } \\
\text { knowledge and resistance skills } \\
\text { to their own lives. }\end{array}$ & $\begin{array}{l}\text { 1. Demonstrate strategies to resist } \\
\text { pressures and to help friends resist } \\
\text { pressures in drinking situations. } \\
\text { 2. Improve strategies for resistance to } \\
\text { offers of alcohol based on student } \\
\text { reactions to and class discussions of } \\
\text { the demonstrations. } \\
\text { 3. Demonstrate ability to integrate alcohol } \\
\text { knowledge and resistance skills into } \\
\text { their own lives. }\end{array}$ & $\begin{array}{l}\text { Review; role playing; class discussions; } \\
\text { individual worksheets; closure. }\end{array}$ \\
\hline
\end{tabular}

\section{Survey}

Before and after administration of the curriculum, students completed questionnaires that covered several psychosocial topics as well as selfreported alcohol use and misuse. Trained project staff administered the questionnaires in students' regular classrooms and answered students' questions in a standardized manner. Students were assured that responses would be confidential, and classroom teachers were positioned so as not to inhibit or bias students' responses. The survey measures reported in this article were from the 10th-grade pretest survey.

\section{Survey Measures}

The AMPS survey data provided information that was used for control variables about subjects' race ( $83 \%$ white, $17 \%$ nonwhite), family structure
(63\% lived with two parents, $37 \%$ did not), alcohol use and misuse, and parental attitudes toward young people's use of alcohol.

To assess frequency and quantity of alcohol use, separate items for beer, wine, and liquor were used, adapted from Rachal et al. (1975). Frequency of alcohol use was asked for each substance (number of times per year added in parentheses): "How often have you had beer (wine, liquor) in the past 12 months? Never (0), a few times a year or less (3), about once a month (12), about once a week (52), 3 or 4 days a week (182), or every day (365)?" Quantity also was assessed separately for each substance (number of drinks added in parentheses): "When you drank beer (wine, liquor) during the past 12 months, how many cans/bottles (glasses, drinks) did you usually have at one time? None (0), less than one drink (0.5), one drink (1), two drinks (2), three or four drinks (3.5), five or six drinks (5.5), or seven or more 
drinks (7)?" Total annual alcohol consumption was estimated by multiplying the number of episodes per year by the number of drinks per episode. Subjects consumed an average of 2.1 drinks per week $(\mathrm{SD}=6.7)$.

Two single alcohol misuse questions were included in this analysis. "During the past 12 months, how many times did you get drunk: never, once, two or three times, four or five times, or six or more times?" "During the past 12 months, how many times have you had five or more drinks in a row: none, once, twice, three to five times, six to nine times, or ten or more times?" Four in 10 students $(40 \%)$ reported getting drunk at least once, and $40 \%$ reported having five or more drinks in a row during the previous 12 months.

The following 10 questions about alcohol misuse during the past 12 months (Greenwald, 1982; Rachal et al., 1975) were used to construct an alcohol misuse index. Responses to and codes for frequency were never (0), once (1), two times (2), or three or more times (3). A 30-point misuse index was constructed by summing the frequency codes (Shope et al., 1994). The mean of the index was $2.1(\mathrm{SD}=3.4)$.

1. How many times did you drink more than you planned to?

2. How many times did you feel sick to your stomach after drinking?

3. How many times did you get talked into doing something you didn't want to do after drinking?

4. How many times did you get into trouble with your friends because of drinking?

5. How many times did you have a friend of the same sex complain about your drinking?

6. How many times did you have a friend of the opposite sex complain about your drinking?

7. How many times did you have someone you were dating complain about your drinking?

8. How many times did you get into trouble with your parents because of your drinking?

9. How many times did you get into trouble with teachers, school counselors, or the principal because of your drinking?

10. How many times did you get into trouble with the police because of your drinking?

Parental attitudes toward young people's alcohol consumption were assessed with the question, "How do your parents feel about kids your age drinking beer, wine, or hard liquor? Do they think it is a very good idea, a good idea, neither a good nor a bad idea, a bad idea, or a very bad idea?" The small percentage $(0.3 \%)$ of students who indicated that their parents approved of their alcohol use was combined with those who were indifferent $(7.7 \%)$; the remainder disapproved $(30 \%)$ or strongly disapproved $(62 \%)$.

\section{Driver History Measures}

The driver history data confirmed sex and age and included information on license tenure, number of and type of violation convictions (offenses), and number of and details about reported crashes. The subjects' mean age was 16.4 years $(\mathrm{SD}=1.0)$ at the time of licensing, and five out of six subjects $(83.8 \%)$ were licensed within 1 year of the intervention. Mean duration of licensure as of 1997 was 7.6 years $(\mathrm{SD}=1.1)$.

Offense data were available only for offenses that resulted in convictions, although the original charge was used in these analyses to avoid biases from the subset of respondents whose resources might have allowed them to "plead down" to lesser charges. Likewise, only crashes reported to the police were included in the analysis. Outcomes considered in these analyses included those that might indicate deliberate risk-taking on the part of the young driver: "serious" offenses, alcohol-related offenses, "at-fault" crashes, single-vehicle crashes, alcohol-related crashes, and combinations thereof. Serious offenses were those that met any of the following criteria: (1) involved use of alcohol, (2) were classed as "serious" by the Secretary of State's office (e.g., reckless driving, vehicular homicide), (3) resulted in 3 or more points assigned to a driver (e.g., speeding in excess of $15 \mathrm{mph}$ over the speed limit), or (4) involved nondriving drug
Table 2. Summary of Survey and Driver History Data, by Treatment Group and Overall

\begin{tabular}{lrrr}
\hline \multicolumn{1}{c}{$\begin{array}{c}\text { Survey measures } \\
\text { Male (\%) }\end{array}$} & $\begin{array}{c}\text { Control } \\
(n=2815)\end{array}$ & $\begin{array}{c}\text { Intervention } \\
(n=1820)\end{array}$ & $\begin{array}{c}\text { Total } \\
(n=4635)\end{array}$ \\
White (\%) & 50.4 & 50.6 & 50.5 \\
Live with both parents (\%) & 84.2 & 86.4 & 85.1 \\
Mean drinks per week & 64.5 & 63.3 & 64.1 \\
Mean alcohol misuse index & 2.0 & 2.2 & 2.1 \\
Parental attitude toward teens' alcohol use (\%) & 2.1 & 2.1 & 2.1 \\
Approve/neither approve nor disapprove & & & \\
Disapprove & 8.0 & 7.9 & 8.0 \\
Strongly disapprove & 29.8 & 30.6 & 30.1 \\
How often drunk during past 12 months (\%) & 62.2 & 61.5 & 61.9 \\
Never & & & \\
Once & 61.2 & 59.0 & 59.6 \\
2-3 times & 12.0 & 12.3 & 12.1 \\
4-5 times & 11.5 & 11.9 & 11.7 \\
$\geq 6$ times & 5.9 & 6.3 & 6.1 \\
Have $\geq 5$ drinks during past 12 months (\%) & 10.5 & 10.5 & 10.5 \\
Never & & & \\
Once & 61.1 & 59.0 & 60.3 \\
2 times & 10.8 & 11.6 & 11.1 \\
3-5 times & 7.0 & 7.1 & 7.0 \\
6-9 times & 9.4 & 9.3 & 9.3 \\
$\geq 10$ times & 4.8 & 5.7 & 5.2 \\
Driver history measures & 6.9 & 7.2 & 7.0 \\
Prelicense offenses (\%) & & & \\
Age at time of licensure (years) ${ }^{\mathrm{b}}$ & 3.06 & 2.91 & 3.00 \\
Mean years of licensure & 16.39 & 16.47 & 16.42 \\
Mean serious offenses & 7.58 & 7.54 & 7.57 \\
Mean alcohol-related offenses ${ }^{\mathrm{a}}$ & 0.76 & 0.77 & 0.76 \\
Mean at-fault crashes & 0.09 & 0.11 & 0.10 \\
Mean single-vehicle crashes & 0.27 & 0.26 & 0.27 \\
Mean alcohol-related crashes & 0.12 & 0.12 & 0.12 \\
\hline & 0.03 & 0.03 & 0.03 \\
\hline
\end{tabular}

Less than $2 \%$ of the overall responses were missing for any one item except for number of drinks per year, which was missing $5 \%$ (236).

${ }^{\text {a }}$ Difference between intervention and control significant at $\alpha=0.05 ;{ }^{\mathrm{b}}$ Difference between intervention and control significant at $\alpha=0.01$.

offenses. Hence, alcohol-related offenses were a subset of serious offenses. At-fault crashes were crashes in which the subject had an offense on the same date as the crash. After a preliminary analysis, described subsequently, serious offenses were selected as the primary outcome of interest. An average of slightly less than one (0.8) serious offense per subject was recorded during the follow-up period.

The "start of driving" is defined as the original license date. The 198 offenses and 38 crashes that occurred before that date were deleted; however, all regression models included an indicator variable for whether an offense occurred before that date. Most prelicense offenses were for driving without a valid license. The few crashes that occurred before licensure were not included to maintain consistency with the start of driving definition.

Table 2 summarizes the survey and driver history data used in these analyses, overall and by intervention group. A comparison of the intervention and control groups indicated that the randomization was largely effective at eliminating differences in potential confounders between the two groups. Those who received the intervention were slightly more likely to be white ( $86 \%$ vs. $84 \%$ ) and older at licensure (mean age 16.5 vs. 16.4), but these differences, although statistically significant, are not meaningful. It was clear that alcohol-related offenses and alcohol-related crashes occurred at very low rates (especially during the earliest driving years), so that it would not be possible to restrict analyses to these measures.

Instead, we placed an emphasis on serious offenses as described previously (which include alcohol-related offenses) and a combination of single-vehicle, alcohol-related, or at-fault crashes, each of which alone had occurred relatively infrequently. Together, this combination of crashes may indicate deliberate, risk-taking behavior on the part of the young driver and are referred to as serious crashes. 

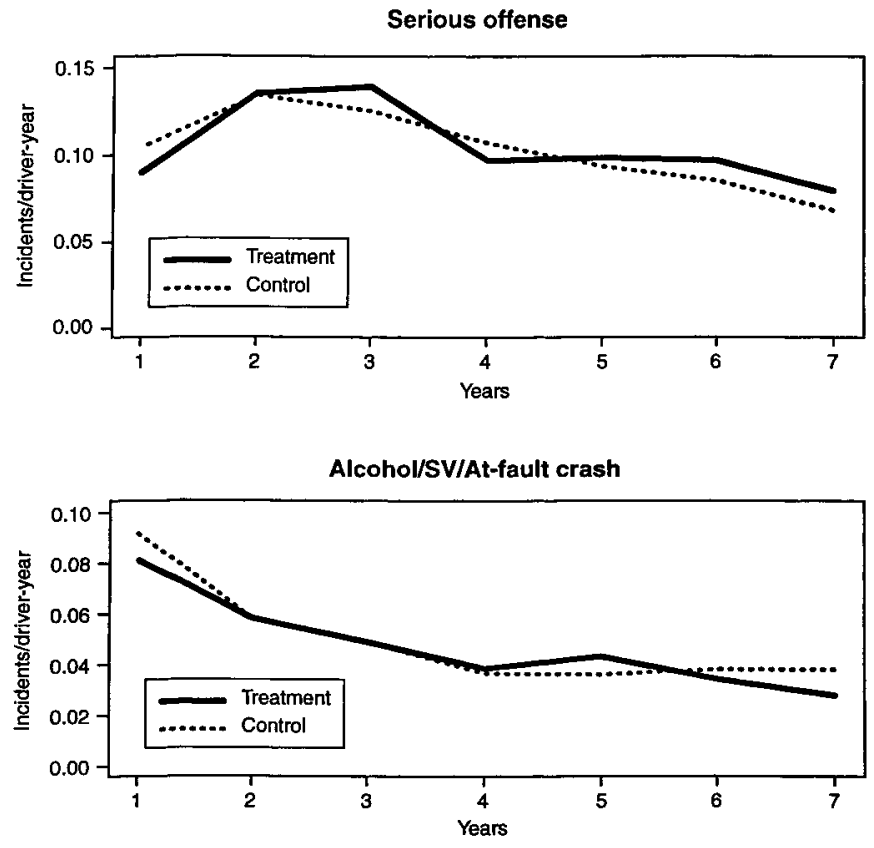

Fig. 1. Unadjusted incident rate by driving year.

\section{Data Analyses}

Poisson regression (McCullagh and Nelder, 1989) was used to model the number of incidents per year as a function of treatment group, duration of license, and potential confounders such as sex, race, alcohol use and misuse, prelicense offenses, age at licensure, family structure, and parental attitudes toward alcohol. These models were fit by using Statistical Analysis System (SAS) Version 6 for Windows (SAS Institute, Cary, $\mathrm{NC})$.

Over- or underdispersion in a selected subset of these models was tested by using overdispersion score tests (Dean, 1992), which indicated that over/underdispersion was not present to a statistically significant degree. Nonetheless, because of the clustered nature of the sample, generalized estimating equation methodology was used to account for the potential correlation among subjects from the same classroom (Diggle et al., 1994). Standard error estimates were constructed by using a robust sandwich-type estimator (Diggle et al., 1994).

Statistical significance was assessed by using likelihood ratio tests for nested Poisson regression models (McCullagh and Nelder, 1989) and Wald tests for generalized estimating equations (Diggle et al., 1994).

\section{RESULTS}

\section{Outcome Measures}

Clearly, the mean number of serious offenses or serious crashes throughout the entire follow-up period is not the best measure of effectiveness of the AMPS intervention, because there was no expectation that the intervention effect could last for 7 years. Instead, if the intervention were effective, incident rates would be reduced for the intervention subjects shortly after licensure, and then, after a period of time with no intervention, would be equalized with control subjects over time.

The crude incident rates for serious offenses and serious crashes are shown in Fig. 1. The rates show the predicted outcome of lower initial rates among the intervention group that then equalize over time. However, estimating
Table 3. Incident Rates by Treatment Group and Relative Risks (RRs) During First Year of Licensure (95\% Confidence Interval in Parentheses)

\begin{tabular}{lcccc}
\hline & \multicolumn{2}{c}{ Rate } & & \\
\cline { 2 - 3 } \multicolumn{1}{c}{ Incident Type } & Intervention & Control & Unadjusted RR & Adjusted RR \\
\hline Serious offense & 0.090 & 0.104 & $0.87(0.70-1.08)$ & $0.80(0.63-1.01)$ \\
Alcohol/single- & 0.082 & 0.092 & $0.89(0.72-1.10)$ & $0.93(0.74-1.16)$ \\
$\quad \begin{array}{l}\text { vehicle/at-fault } \\
\text { crash }\end{array}$ & & & & \\
\hline
\end{tabular}

the incident risk for the intervention group relative to the control group for just the first year of licensure showed that only serious offenses differed (marginally) significantly (see Table 3). Those subjects in the intervention group had only $80 \%$ of the risk of incurring a serious offense $(p=0.056)$ relative to those in the control group, after we adjusted for sex, race, alcohol use/misuse, age at licensure, presence of prelicense offenses, family structure, and parental attitudes toward alcohol use.

\section{Effect of Intervention on Serious Offenses}

When we focused on serious offenses as the primary outcome of interest, Table 4 shows that the marginally significant effect of the intervention appears to last for only 1 year. When we examined the possibility that the intervention effect might differ depending on the subject's sex, family structure, parental attitudes toward young people's alcohol use, or current alcohol use, we found no evidence that the effect of the intervention on serious offenses differed by sex or family structure. However, the significant effect of the intervention on serious offenses in the first year of driving was substantially stronger among those subjects who reported less than one drink per week. They had a treatment effect relative risk (RR) during their first year of licensure of 0.63 (confidence interval $[\mathrm{CI}]=0.47-0.85$, $p=0.002$ ), whereas those who averaged one or more drinks per week had a first-year treatment effect RR of 1.19 $(\mathrm{CI}=0.82-1.75, p=0.34 ; p$ value for between-group difference $=0.009)$. Similarly, those subjects whose parents showed no disapproval of alcohol use showed a stronger treatment effect $(\mathrm{RR}=0.36, \mathrm{CI}=0.18-0.72, p=0.004)$, than those whose parents disapproved $(\mathrm{RR}=0.87, \mathrm{CI}=$ $0.70-1.10, p=0.24 ; p$ value for between-group differences $=0.032$ ). No significant treatment effect was found for either group after the first year.

Figure 2 portrays the two interactions together. The figure shows that subjects in the treatment group who drank less than one drink per week but whose parents did not disapprove of alcohol use $(n=201)$ had a first-year RR for serious offense of 0.13 ( $\mathrm{CI}=0.03-0.51, p=0.004)$ compared with those in the control group. Those drinking less than one drink per week but with disapproving parents $(n=2976)$ had a first-year RR for serious offense of 0.71 $(\mathrm{CI}=0.52-0.95, p=0.022)$. Those drinking one or more drinks per week with nondisapproving parents $(n=142)$ had a first-year RR of 0.87 ( $\mathrm{CI}=0.34-2.21, p=0.77$ ), whereas those drinking one or more drinks per week with 
Table 4. Percentages, Mean Number, and Relative Risk (RR, Treatment vs. Control) of Serious Offenses by Year of Driving Tenure (95\% Confidence Interval in Parentheses)

\begin{tabular}{|c|c|c|c|c|c|c|}
\hline \multirow[b]{3}{*}{ Year } & \multirow[b]{3}{*}{$n$} & \multicolumn{4}{|c|}{ Serious offenses } & \multirow[b]{3}{*}{ Adjusted RR } \\
\hline & & \multicolumn{2}{|c|}{ Treatment } & \multicolumn{2}{|c|}{ Control } & \\
\hline & & $\%$ with any & Mean & $\%$ with any & Mean & \\
\hline 1 & 4631 & 7.8 & 0.090 & 9.1 & 0.104 & $0.80(0.63-1.01)$ \\
\hline 2 & 4629 & 11.5 & 0.134 & 12.1 & 0.134 & $1.00(0.83-1.20)$ \\
\hline 3 & 4612 & 11.6 & 0.138 & 10.8 & 0.124 & $1.14(0.96-1.35)$ \\
\hline 4 & 4603 & 8.4 & 0.095 & 9.2 & 0.107 & $0.92(0.76-1.12)$ \\
\hline 5 & 4582 & 8.6 & 0.098 & 8.4 & 0.093 & $1.02(0.82-1.27)$ \\
\hline 6 & 4523 & 8.3 & 0.096 & 7.3 & 0.085 & $1.11(0.90-1.38)$ \\
\hline 7 & 4340 & 6.8 & 0.076 & 5.8 & 0.066 & $1.14(0.89-1.47)$ \\
\hline
\end{tabular}

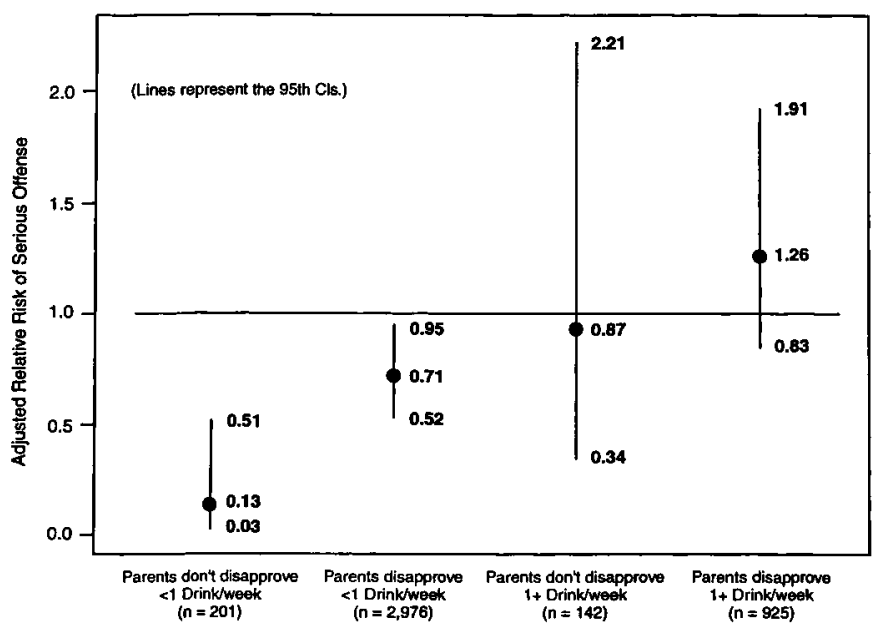

Fig. 2. Risk of first-year serious offense by treatment relative to control: Alcohol use and parental attitudes toward alcohol use.

disapproving parents $(n=925)$ had a first-year $\mathrm{RR}$ of 1.26 $(\mathrm{CI}=0.83-1.91, p=0.27$ ). (All analyses but the first controlled for sex, race, family structure, prelicense offenses, and age at licensure. Prelicense offenses were dropped from the low-drinking, nondisapproving-parents group because an insufficient number were present to estimate the effect.)

These results indicate that, after we adjusted for known confounders, intervention subjects in the low-drinking, nondisapproving-parents group had an average of 143 fewer serious offenses than expected per 1000 subjects. Those intervention subjects in the low-drinking, disapproving-parents group had 24 fewer serious offenses than expected per 1000 subjects. Those in the drinking, nondisapproving-parents group had 22 fewer serious offenses than expected per 1000 subjects; whereas those in the drinking, disapproving-parents group had 27 more serious offenses than expected per 1000 subjects. Thus the intervention overall appears to have reduced the number of first-year-of-license serious offenses by 18 per 1000 intervention students. (These estimates are computed by estimating the absolute rates for the treatment and nontreatment groups from the Poisson regression models, with the values for the confounders set to the means within each alcohol use-by-parental attitude cell. The overall rate dif- ference is the weighted mean of the interaction cell differences, weighted by the cell size.)

\section{DISCUSSION}

Previous analyses have shown that the high school alcohol misuse prevention curriculum was effective in increasing students' alcohol misuse prevention knowledge and alcohol refusal skills and in reducing alcohol misuse (Shope et al., 1993, 1996b). The analyses reported here attempted to determine if those positive effects reached into alcoholrelated or other dangerous driving behaviors, and, if so, how long such effects lasted. After we examined outcomes of serious offenses and serious crashes, we found the AMPS curriculum to reduce the risk of serious offenses during the first year of licensure by an estimated $20 \%$, adjusting for sex, race, alcohol use/misuse, age at time of licensure, family structure, and parental attitudes toward young people's alcohol use. In a finding similar to that of others (Williams et al., 1999), the effect of the curriculum was particularly strong among those students who were drinking less than one drink per week on average before the curriculum. The treatment effects disappeared after the first year of licensure. These driving outcome findings indicated that teenagers who had not yet started routine drinking benefited the most from a 10th-grade, schoolbased intervention designed to reduce alcohol misuse. In contrast, those who were already drinking one or more drinks per week showed no benefit in their driving outcomes. This finding fits with others in the prevention and problem behavior literature-young people who had not started drinking were amenable to the intervention program's messages about drinking/driving and other risky behaviors.

Interestingly, among both those who drank less than one drink per week and those who drank more than one drink per week, students who reported that their parents had expressed disapproval of young people's drinking demonstrated less benefit from the program than did those whose parents had not expressed disapproval. This finding could be explained by the students' self-reported drinking itselfthose who drank more probably had generated an opportunity to hear from their parents about parental attitudes regarding young people's drinking. Those who drank less 
may not have heard their parents' attitudes expressed. Students who reported that their parents had not expressed disapproval of young people's drinking were in the minority, and they represented only $7 \%$ of the total number of subjects. The $20 \%$ of students who drank in the face of parental disapproval and showed little benefit to their driving from the intervention program were very likely students who were testing limits and exhibiting other problem behaviors (Jessor et al., 1991). Indeed, in other analyses of a subset of our study subjects, alcohol use during high school was shown to be related to subsequent poor driving outcomes (Shope et al., 1996c). It is possible that such students could react negatively to a prevention program, an outcome that should be carefully guarded against. These analyses also indicated that the positive effect of the intervention on driving behavior appears to diminish after 1 year of licensure, not surprising given that there was no follow-up intervention.

It is perhaps unsurprising, although unfortunate, that no significant treatment effects were found for crash outcomes. There is evidence to suggest that crashes are less predictive of poor driving behavior than offenses (Elliott et al., 2000). This is probably because poor driving is more likely to lead to an offense than a crash and because even good drivers can be involved in a crash through little or no fault of their own.

Although the high school alcohol misuse prevention program discussed here did not reduce the average rate of serious offenses in the first year of driving at a statistically significant $(\alpha=0.05)$ level, the rate of first-year serious offenses was reduced significantly among those who consumed less than one drink of alcohol per week or whose parents did not disapprove of alcohol use by 10th graders. These results suggest that a high school alcohol misuse prevention program can positively affect driving outcomes, even when that behavior is not the sole program focus. Future programs could be adapted to accommodate students' differences about their current alcohol use and parental attitudes toward teen drinking. Such programs also should be augmented by follow-ups after students have acquired some driving experience and by other communitybased programs.

\section{ACKNOWLEDGMENT}

We gratefully acknowledge the support and assistance of the local school district staffs, the Michigan Secretary of State's Office, and the research staff.

\section{REFERENCES}

Dean CB (1992) Testing for overdispersion in Poisson and binomial regression models. J Am Stat Assoc 87:451-457.

Dielman TE, Shope JT, Leech SL, Butchart AT (1989) Differential effectiveness of an elementary school-based alcohol misuse prevention program. J Sch Health 59:255-263.

Diggle PJ, Liang K-Y, Zeger SL (1994) Analysis of Longitudinal Data. Oxford University Press, Oxford, UK.
Elliott MR, Waller PF, Raghunathan TE, Shope JT (2000) Predicting offenses and crashes from young drivers' offense and crash histories. J Crash Prevention and Injury Control, in press.

Evans RJ (1976) Smoking in children: Developing a social psychological strategy of deterrence. Prev Med 5:122-127.

Greenwald MA (1982) Minimizing Alcohol Problems and Smoking: Final Report Year II. University of Pittsburgh, Pittsburgh, PA.

Institute of Medicine (1999) Reducing the Burden of Injury (Bonnie RJ, Fulco DE, Liverman CT eds). National Academy Press, Washington DC.

Insurance Institute for Highway Safety (1998) Fatality Facts: Teenagers. Available at: http://www.iihs.org/facts/teen.html. Accessed Feb. 11, 2000

Jessor R, Donovan JE, Costa FM (1991) Beyond Adolescence: Problem Behavior and Young Adult Development. Cambridge University Press, New York.

Klepp KI, Kelder SH, Perry CL (1995) Alcohol and marijuana use among adolescents: Long-term outcomes of the class of 1989 study. Ann Behav Med 17:19-24.

Mann RE, Vingilis ER, Leigh G, Anglin L, Blefgen H (1986) Schoolbased programmes for the prevention of drinking and driving: Issues and results. Accid Anal Prev 18:325-337.

McCullagh P, Nelder JA (1989) Generalized Linear Models. Chapman and Hall, London.

Monitoring the Future Study (1999) Available at: http:/monitoringthefuture.org. Accessed Feb. 11, 2000.

National Highway Traffic Safety Administration (1998) Traffic Safety Facts 1997. Department of Transportation, Washington, DC.

Newman IM, Anderson CS, Farrell KA (1992) Role rehearsal and efficacy: Two 15-month evaluations of a ninth-grade alcohol education program. J Drug Educ 22:55-67.

Perry CL, Williams CL, Komro KA, Veblen-Mortenson S, Forster JL, Bernstein-Lachter R, Pratt LK, Dudovitz B, Munson KA, Farbakhsh K, Finnegan J, McGovern P (2000) Project Northland high school interventions: Community action to reduce adolescent alcohol use. Health Educ Behav 27:29-49.

Rachal JV, Williams JR, Brehm ML, Cavanaugh E, Moore RP, Eckerman WC (1975) A National Study of Adolescent Drinking Behavior, Attitudes and Correlates: Final Report. National Institute on Alcohol Abuse and Alcoholism, Rockville, MD.

Sheehan M, Schonfeld C, Ballard R, Schofield F, Najman J, Siskind V (1996) A three year outcome evaluation of a theory based drink driving education program. J Drug Educ 26:295-312.

Shope JT, Copeland LA, Dielman TE (1994) Measurement of alcohol use and misuse in a cohort of students followed from Grade 6 through Grade 12. Alcohol Clin Exp Res 18:726-733.

Shope JT, Copeland LA, Maharg R, Dielman TE (1996a) Effectiveness of a high school alcohol misuse prevention program. Alcohol Clin Exp Res 20:791-798.

Shope JT, Copeland LA, Maharg R, Dielman TE, Butchart AT (1993) Assessment of adolescent refusal skills in an alcohol misuse prevention study. Health Educ Q 20:373-390.

Shope JT, Copeland LA, Waller PF (1996b) A high school alcohol misuse prevention program reduces subsequent driving offenses (abstract). Alcohol Clin Exp Res (Suppl 2) 20:144A.

Shope JT, Dielman TE, Butchart AT, Campanelli PC (1992) An elementary school-based alcohol misuse prevention program: Follow-up evaluation. J Stud Alcohol 53:106-120.

Shope JT, Dielman TE, Maharg R, Leech SL, Miller M (1989) Alcohol Misuse Prevention: Booster Curriculum Guide for Tenth-Grade. University of Michigan, Ann Arbor.

Shope JT, Waller PF, Lang SW (1996c) Alcohol-related predictors of adolescent driving: Gender differences in crashes and offenses. Accid Anal Prev 28:755-764. 
Williams CL, Perry CL (1998) Lessons from Project Northland: Preventing alcohol problems during adolescence. Alcohol Health Res World 22:107-116.

Williams CL, Perry CL, Farbakhsh K, Veblen-Mortenson S (1999) Project Northland: Comprehensive alcohol use prevention for young adolescents, their parents, schools, peers and communities. J Stud Alcohol Suppl 13:112-124.
Wodarski JS, Bordnick PS (1994) Teaching adolescents about alcohol and driving: A 2-year follow-up study. Res Soc Work Prac 4:28-39.

Yates BA, Dowrick PW (1991) Stop the drinking driver: A behavioral school-based prevention program. J Alcohol Drug Educ 36:12-19.

Young C (1991) Alcohol, drugs, driving and you: A comprehensive program to prevent adolescent drinking, drug use, and driving. J Alcohol Drug Educ 36:20-25. 